Revue

Revue de l'histoire des religions

de Ihistoire des religions

$4 \mid 2012$

Varia

Actes et Passions des martyrs chrétiens des premiers siècles, introduction, traduction et notes de Pierre MARAVAL

Paris, Les Éditions du Cerf (« Sagesses chrétiennes »), 2010, 19,5 cm, 392 p., $29 €$, ISBN 978-2-204-09233-3.

Cécile Lanéry

\title{
OpenEdition
}

Journals

Édition électronique

URL : https://journals.openedition.org/rhr/7995

DOI : $10.4000 /$ rhr.7995

ISSN : 2105-2573

Éditeur

Armand Colin

Édition imprimée

Date de publication : 1 décembre 2012

Pagination : $537-539$

ISBN : 978-2200-92796-7

ISSN : 0035-1423

Référence électronique

Cécile Lanéry, «Actes et Passions des martyrs chrétiens des premiers siècles, introduction, traduction et notes de Pierre maRAVAL », Revue de l'histoire des religions [En ligne], 4 | 2012, mis en ligne le 24 janvier 2013, consulté le 21 septembre 2021. URL : http://journals.openedition.org/rhr/7995 ; DOI : https:// doi.org/10.4000/rhr.7995

Ce document a été généré automatiquement le 21 septembre 2021.

Tous droits réservés 


\section{Actes et Passions des martyrs chrétiens des premiers siècles, introduction, traduction et notes de Pierre}

\section{MARAVAL}

Paris, Les Éditions du Cerf (« Sagesses chrétiennes »), 2010, 19,5 cm, 392 p., $29 €$, ISBN 978-2-204-09233-3.

\section{Cécile Lanéry}

\section{RÉFÉRENCE}

Actes et Passions des martyrs chrétiens des premiers siècles, introduction, traduction et notes de Pierre MARAVAL, Paris, Les Éditions du Cerf (« Sagesses chrétiennes »), 2010, 19,5 cm, 392 p., $29 €$, ISBN 978-2-204-09233-3.

Ce volume présente un choix éclectique d'Actes et de Passions de martyrs, utilement traduits en français à l'intention d'un public non-spécialiste. Les 27 textes, tant latins que grecs, ont été sélectionnés par P.M. pour illustrer différentes persécutions antichrétiennes, de 64 à 320 environ. D'authenticité variable - certains sont des procèsverbaux à peine retouchés, d'autres des récritures postérieures de plusieurs siècles aux évènements rapportés - ils intéressent des régions variées de l'Empire (Italie, Asie, Gaule, Afrique, Espagne, Pannonie, Grèce, Égypte, Arménie, Palestine) ; la Sicile, qui eût pu être représentée par Euplus, martyr à Catane en 304, est absente, mais cette anthologie ne prétend pas être exhaustive. L'ensemble est introduit par une brève histoire des persécutions durant la période considérée, et par une présentation concise de la littérature martyriale ancienne. Peut-être pourrait-on juste nuancer l'affirmation de la p. 29-30, selon laquelle «à Rome, la lecture liturgique des Passions n'[était] pas admise avant le $\mathrm{IX}^{\mathrm{e}}$ siècle » : en réalité, elle était tolérée, bien avant cette date, dans les sanctuaires cimétériaux et dans les paroisses urbaines, le jour anniversaire du saint 
auquel l'édifice était consacré (cf. B. DE GAIFFIER, dans Analecta Bollandiana, t. 87, 1969, p. 63-78).

Les traductions ont été effectuées à partir d'éditions non reproduites dans le volume, mais correctement citées; seule l'édition de la Passion latine d'Agathonice (traduite partiellement, p. 97) n'est pas indiquée (P.M. l'a sans doute tirée du volume de $\mathrm{H}$. Musurillo, The Acts of the Christian Martyrs, Oxford, 1972, p. 34). Pour Saturnin, le traducteur s'est malheureusement basé sur le texte composite et artificiel publié par P. CABAU en 2001 ; il eût sans doute mieux valu suivre celui d'A. FÁBREGA GRAU, Pasionario hispánico, Madrid - Barcelona, 1955, t. 2, p. 57-9 (cf. l'étude du dossier de Saturnin par A.-V. GILles-RAYNAL, dans Miracles, Vies et réécritures dans l'Occident médiéval, Ostfildern, 2006, p. 364). Les textes traduits sont annotés et précédés d'une introduction synthétique, en général bien informée. Toutes les traductions sont de P.M., à l'exception des Actes de Gallonius (découverts et publiés en 2004 par P. CHIESA, dans Sanctorum, t.1, p.241-68), cités dans la traduction posthume de S. LANCEL. Ces traductions sont fidèles, au prix de quelques maladresses (p. 42, dans MPol. II.2, l'expression « veines internes » traduit sans doute trop littéralement le grec « $\tau \tilde{\omega} v$ ह̌ $\sigma \omega$ $\varphi \lambda \varepsilon \beta \tilde{\omega} v »)$; le même mot est parfois traduit différemment à quelques lignes d'intervalle (p. 93, dans ACarpos 8 et 17, l'adjectif « oỉkzía » est rendu par « innée » puis, plus exactement, par « propre »; p. 234, dans AMaxim. 4 et 5, « officium » est traduit par " office " puis par " officier »). On relève quelques rares erreurs : p. 96 (ACarpos 42),

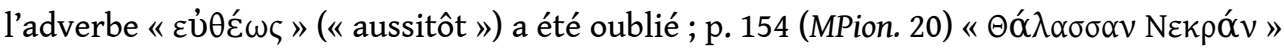
pouvait être tout simplement traduit par «Mer Morte» plutôt que par «lac

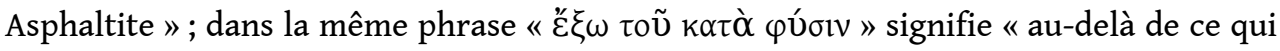
est naturel », «à un degré surnaturel », et non " selon sa nature »; p. 206 (PFruct. III.2), l'expression « quarta feria » désigne le mercredi et non le vendredi; p. 266 (PJules I.3), la traduction «je ne nie pas être autre chose que ce que je suis» est rigoureusement exacte, mais basée sur un texte manifestement corrompu ( « non nego me aliud esse quam sum » : il faudrait corriger « non nego » en " non dico », et comprendre « je ne dis pas être autre chose que ce que je suis») ; p. 275 (PIrén. V.4), "productus de ecclesia tua » signifie « issu de ton Église " plutôt que « comme prémices de ton Église »; p. 282

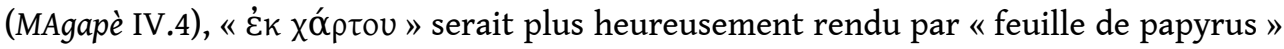
plutôt que par «feuille de papier»; p. 282 (MAgapè V.1), l'énumération des écrits saisis

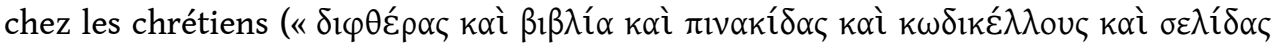
$\gamma \rho \alpha \varphi \tilde{\omega} v »$ : «tablettes, livres, parchemins, codices, feuillets ») pourrait être traduite de manière plus précise par «parchemins, livres (sous forme de rouleaux ou de codices), tablettes, carnets (petits codices), feuillets». Pour un compte rendu détaillé des traductions de Passions africaines (AScil., PPerp., ACypr., PMarien), voir la «Chronica Tertullianea et Cyprianea", à paraître dans la Revue des Études augustiniennes et patristiques en 2012.

3 Les traductions sont elles-mêmes suivies d'une brève bibliographie, avantageusement complétée par les titres cités dans les notes. L'information est à jour, sans érudition superflue. Signalons juste un lapsus, p. 375 (le volume précité de musuRILlo est paru en 1972 et non en 1982), et ajoutons que la collection dirigée par G. PHILIPPART (Hagiographies. Histoire internationale de la littérature hagiographique latine et vernaculaire en Occident des origines à 1550), est aujourd'hui riche de 5 volumes; le $3^{\text {e }}$, paru en 2001, contient précisément une étude de S. BOESCH GAJANO sur les débuts de la littérature hagiographique (avec des notices pour Fructueux, Irénée, Jules, Carpos et Philéas). Un 
index des noms de martyrs et de confesseurs clôt le volume; peut-être aurait-on pu aussi, puisque ces traductions s'adressent à des non-spécialistes, lui adjoindre une carte sommaire de l'Empire romain, permettant de situer, au moins de manière approximative, les différents lieux évoqués dans l'ouvrage. Tel qu'il est, ce volume n'en rendra pas moins service aux lecteurs peu familiers des langues anciennes, mais curieux de découvrir les premiers monuments de la littérature hagiographique chrétienne.

\section{AUTEURS}

\section{CÉCILE LANÉRY}

Institut de recherche et d'histoire des Textes. 